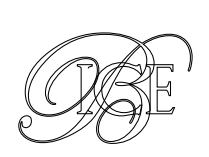

\author{
Enrique Fanjul*
}

\title{
DE LOS PRIMEROS GRANDES PROYECTOS A TIANANMEN
}

El periodo que me tocó vivir en China, a fines de los años ochenta, estuvo marcado por tres desarrollos principales: la firma de los primeros grandes contratos de proyectos por parte de empresas españolas — después de varios años de dificultades_, el establecimiento del primer protocolo financiero para exportaciones españolas y la crisis de Tiananmen.

Cuando me incorporé a mi puesto, a mediados de 1987, existía un cierto escepticismo sobre las relaciones económicas con China. Un par de años antes se había producido la visita del presidente del Gobierno español, Felipe González, al frente de una gran delegación empresarial.

Durante la visita se planteó y estudió, por ambas Administraciones, una lista de proyectos para ser realizados por empresas españolas, que serían financiados con créditos concesionales españoles, en condiciones muy favorables. En su momento, el viaje de Felipe González tuvo un gran impacto entre los círculos empresariales. Se crearon grandes expectativas acerca de lo que se podía obtener en el mercado chino. Y quizás hubo una cierta infravaloración de los obstáculos.

De la amplia serie de proyectos considerados durante esa visita del presidente del

*Técnico Comercial y Economista del Estado.

Versión de diciembre de 2017.
Gobierno solo uno llegaría a tener éxito: una planta de procesamiento de cítricos en la provincia de Zhejiang, que en realidad ya se hallaba en una fase avanzada de negociación cuando se produjo la visita del presidente.

Las expectativas optimistas que se crearon con el viaje del presidente del Gobierno se vieron sensiblemente rebajadas con el paso del tiempo por los problemas y obstáculos a los que se enfrentaba España en su empeño de implantarse en China.

Nos enfrentábamos en primer lugar a un problema de imagen. España era poco conocida, y el escaso conocimiento que se tenía de ella, en una China obsesionada por conseguir las tecnologías más modernas, no la situaba como una nación avanzada desde el punto de vista industrial y tecnológico. Las empresas chinas no estaban, en principio, inclinadas a considerar los productos tecnológicos españoles, cuando tenían a su disposición productos alemanes o estadounidenses de mayor prestigio y reconocimiento.

Los resultados no se produjeron con la rapidez que muchos habían esperado. Varios de los proyectos que se pusieron en curso de negociación terminaron fracasando, por diversos motivos.

Cuando llegué a China, el proyecto que ocupaba un lugar central era la planta de materias $\triangleright$ 
primas para detergentes de Fushun (provincia de Liaoning, en la región que anteriormente se llamaba Manchuria). Afortunadamente, en este caso hubo un resultado satisfactorio. En marzo de 1988, la empresa española Técnicas Reunidas, una compañía veterana y con sólida experiencia en los mercados internacionales, firmó el contrato. Era un proyecto importante por su tamaño, con un componente tecnológico destacado y que avalaba la capacidad de España en el campo industrial. Por parte de la Administración española se hizo un gran esfuerzo para que el proyecto tuviera éxito, tanto mediante apoyo institucional como, sobre todo, el ofrecimiento de unas condiciones de financiación muy ventajosas.

Una sensación de alivio se extendió entre los responsables económicos del Gobierno chino y del Gobierno español. Por fin, y tras una larga lista de proyectos que, por unos y otros motivos, se habían ido quedando por el camino, España firmaba su primer gran proyecto en China.

Para un consejero comercial el trabajo en China resultaba apasionante, por la involucración que suponía. Los aspectos institucionales eran, y siguen siendo, muy importantes en China, por su sistema político, su cultura, el papel del Gobierno en la economía, etcétera. Pero, además, en esta época, los proyectos que se plantearon y negociaron se financiaban, en su inmensa mayoría, con créditos concesionales del Fondo de Ayuda al Desarrollo (FAD), que eran créditos del Gobierno español al Gobierno chino. Esto suponía una intervención muy directa de las dos Administraciones, y el Consejero Comercial era el representante en China de la Administración comercial española.

En uno de los proyectos en curso de negociación en esa época -la única vez en mi vida de consejero comercial- me mandaron un telegrama cifrado desde nuestros servicios centrales. El mensaje me lo enviaron desde la Secretaría de Estado de Comercio vía el embajador, ya que en una oficina comercial no se utilizan mensajes cifrados, y no teníamos, por tanto, instrumentos para descifrar. En el mensaje me indicaban que estaba autorizado a mejorar las condiciones de financiación del proyecto (y me señalaban lógicamente en qué términos concretos) si consideraba que ello era necesario para el éxito de la negociación. Era una muestra del interés con que la Administración seguía, en general, las negociaciones de los proyectos de las empresas españolas.

El proyecto de Fushun abrió las puertas, y le siguieron, con relativa rapidez, otros proyectos, en sectores como las telecomunicaciones o la energía, por parte de empresas como el grupo INI, Foster Wheeler Iberia o Alcatel Standard Eléctrica.

En el marco de esta labor de apoyo institucional, una de las tareas habituales del consejero comercial era, por ejemplo, acudir a banquetes y reuniones entre empresas chinas y españolas. Su presencia tenía un significado claro y sencillo: manifestar apoyo institucional. Asistí a innumerables banquetes, invitado bien por una empresa española, bien por una empresa o corporación china. Mi «función», básicamente, consistíaenindicarque respaldábamos a la empresa española, que esta era muy buena y muy competente en su actividad, etcétera. Si ya se planteaba algún proyecto concreto, y si éste no presentaba inconvenientes - como era la mayoría de los casos-, yo añadía que por parte de las autoridades españolas estábamos dispuestos a estudiar su financiación con créditos FAD. Para los chinos, la presencia de un representante de la Administración española $\square$ 
constituía un signo de que la empresa española era "seria», de que estaba respaldada por las autoridades españolas y de que la disponibilidad de financiación concesional era una opción posible.

Eran muy importantes el apoyo institucional, la financiación de los proyectos con créditos FAD y otros aspectos como las dificultades que presentaba el mercado chino para obtener información, para realizar gestiones, para comunicación (por las dificultades del idioma), etcétera: por todos estos factores buena parte de las empresas españolas que iban a China «pasaban» por la Oficina Comercial. Nos pedían que les arregláramos citas, que acompañáramos a algunas de ellas (con frecuencia a banquetes, como ya he comentado), que les buscáramos información, que las ayudáramos a tramitar un visado para un cliente, y un largo etcétera de actividades y gestiones. Recordemos que estamos hablando de una época en la que las facilidades para la comunicación, para la obtención de información o para organizar viajes por el interior del país eran muy inferiores a las que existen hoy en día.

Como era lógico, la relación con muchos de estos empresarios trascendía el trabajo. En aquella época había muy pocos lugares en Pekín a los que los extranjeros podíamos ir, como a cenar o tomar una copa; apenas media docena de hoteles. Mi mujer y yo invitábamos con frecuencia a estos empresarios a nuestra casa, a cenar, a tomar una copa. Organizábamos partidas de mus (recuerdo un torneo de mus, un fin de semana, en el que tuvimos cuatro mesas, es decir, dieciséis jugadores). Hicimos muy buenos amigos, y en unos cuantos casos he conservado esa amistad a lo largo de los años. Es uno de los buenos recuerdos (de los muchos) que guardo de mi etapa en Pekín.

\section{EI liderazgo de la Administración}

En el marco del apoyo institucional, el liderazgo de la Administración española se tradujo, como he indicado, en un fuerte apoyo financiero mediante los créditos FAD (Fondo de Ayuda al Desarrollo). Estos créditos blandos fueron necesarios para situarse en línea de competitividad. La nueva China de la reforma era un mercado muy atractivo desde el punto de vista comercial, lo cual se traducía, entre otras cosas, en la disponibilidad de una oferta financiera ventajosa, con un elevado volumen de créditos concesionales, por parte de los principales países occidentales. Sin los créditos FAD las empresas chinas, que conocían muy poco acerca de la capacidad industrial de España, difícilmente habrían tomado en consideración a las empresas españolas como potenciales suministradores de interés.

El apoyo financiero se instrumentó en una primera fase proyecto a proyecto; es decir, en las reuniones entre las dos Administraciones. La parte china proponía proyectos concretos y la parte española ratificaba su posible financiación mediante un crédito «mixto» (es decir, que combinaba créditos concesionales del Fondo de Ayuda al Desarrollo y créditos comerciales concedidos por la banca).

Tras firmarse en 1988 una serie de contratos, a principios de 1989, con Apolonio Ruiz Ligero como secretario de Estado de Comercio español, se estableció un protocolo financiero, mediante el cual la Administración española ponía a disposición del Gobierno chino una cifra global de créditos mixtos para un período determinado de tiempo. De esta forma, se sistematizaba la oferta financiera, y el Gobierno chino sabía cuál era el importe de financiación española con que podía contar. Por otra parte, la existencia de un protocolo financiero, $\square$ 
con unas cifras importantes, tenía un efecto "propagandístico», y contribuyó a despertar un mayor interés entre las empresas e instituciones chinas por la oferta de las empresas españolas.

En concreto, el primer acuerdo financiero estableció una cifra de 450 millones de dólares para un periodo de dos años (de esos $450 \mathrm{mi}$ llones, 200 eran de créditos FAD y 250 de créditos a la exportación en condiciones OCDE). Posteriormente, se continuaría negociando, hasta hace no mucho tiempo, acuerdos financieros por períodos bianuales.

El primer protocolo financiero se acordó a comienzos de 1989. Su gestación se produjo de una manera muy rápida y directa. Fue durante una visita oficial a Madrid de un viceministro chino de comercio exterior. La idea de un protocolo financiero, con el fin de dar más difusión y atractivo a la financiación española, me la había sugerido en Pekín el agregado comercial de la Oficina Comercial, Ernesto Giménez Burgos. Pues bien, en Madrid, en el despacho del secretario de Estado de Comercio, Apolonio Ruiz Ligero, antes de que se reuniera con la delegación china encabezada por el viceministro, yo le propuse la idea. Apolonio Ruiz Ligero - conocido universalmente entre la Administración y las empresas españolas como Poli, un gran secretario de Estado, con una conciencia muy clara de que la Administración debía apoyar con decisión a las empresas españolas- interpretó inmediatamente las ventajas que podía tener establecer un programa financiero, en vez de ir aprobando las operaciones de forma individual. Recuerdo que para concluir me dijo algo así como: «Claro, así vestimos mejor la financiación...»".

En la posterior reunión con la delegación china Ruiz Ligero propuso al viceministro chino el establecimiento de un programa financiero para apoyar exportaciones de proyectos por parte de empresas españolas. El viceministro aceptó encantado, y fue así cómo se puso en marcha el programa financiero, el primero de una larga serie.

Un elemento clave en la política de financiación de España fue el establecimiento de líneas especiales para proyectos pequeños y medianos, una iniciativa que se revelaría como muy acertada y adecuada a las condiciones del mercado chino y a las oportunidades de las empresas españolas. Existía una serie de sectores de maquinaria que ofrecían buenas posibilidades para la industria española. Se trataba de sectores de maquinaria para la industria textil, industria agroalimentaria, materiales de construcción, etcétera. Una característica de los proyectos en estos sectores es que su tamaño es relativamente pequeño. $\mathrm{Si}$ para cada uno de ellos hubiera que realizar todo el procedimiento de tramitación administrativa de un crédito FAD, la complicación burocrática y los retrasos podrían haberse convertido en un factor distorsionante.

Por ello, en la Comisión Mixta que se celebró en otoño de 1987 (en la que se reunieron los responsables de las relaciones económicas bilaterales de los dos países) la parte española propuso el establecimiento de una línea especial de 20 millones de dólares para proyectos pequeños y medianos, de hasta un máximo de cinco millones de dólares por proyecto individual. Esta línea se tramitó como un único crédito FAD, y luego se iban imputando a ella operaciones, simplificando y agilizando el proceso de tramitación. Este tipo de líneas para proyectos pequeños y medianos se mantendría y renovaría durante mucho tiempo, permitiendo la financiación de muchas docenas de proyectos, con cifras muy elevadas de exportación de maquinaria española. 
En mi opinión, los créditos FAD cumplieron en China - con un alto grado de éxito en líneas generales, como en la mayoría de los países en los que fueron utilizados- una función de apoyo a la exportación, unida a su otra función de ayuda al desarrollo, ya que efectivamente permitieron la ejecución de proyectos que favorecían el desarrollo económico de China.

\section{España y la crisis de Tiananmen}

En 1989 se produjeron los trágicos sucesos de Tiananmen. Entre mediados de abril y principios de junio, los estudiantes se manifestaron en las calles de Pekín, atrayendo al cabo de algunas semanas a amplios sectores de la población. El 4 de junio las autoridades chinas decidieron terminar con las manifestaciones estudiantiles. Los violentos sucesos de esos primeros días de junio, transmitidos a todo el mundo por los medios de comunicación, conmocionaron a la opinión pública internacional. Los países occidentales adoptaron medidas de sanción contra China. Las sanciones económicas comprendieron la suspensión de nuevos proyectos de cooperación y la congelación de los programas financieros. En el caso concreto de España, y en lo que se refiere a nuestra presencia económica, las sanciones amenazaban con abortar el despegue iniciado en 1988.

¿Qué labor desarrollamos en la Oficina Comercial durante aquellos difíciles momentos? La verdad es que a medida que el periodo de manifestaciones y desorden se prolongaba, la actividad normal de la oficina se fue paralizando. Dejamos de tener misiones comerciales, visitas de empresas y participaciones en ferias. Después del estallido de los incidentes violentos, el 4 de junio, y tras unos días de mucha incertidumbre mientras se aclaraba la situación, empezamos a recuperar la normalidad, aunque con lentitud.

Durante esos días de principios de junio sí tuvimos un trabajo intenso, desarrollando una labor que era más bien consular: atender a los técnicos y representantes de empresas que estaban en China, normalmente trabajando en proyectos o en joint ventures con participación de empresas españolas. Además, contaba con muy poco personal en la oficina. Una parte del personal se encontraba de vacaciones; como la actividad había bajado mucho en las semanas anteriores, se había aprovechado para que tomaran vacaciones. De los que estaban en Pekín, varios decidieron marcharse de China, utilizando el plan de evacuación que organizó la Administración española, que recomendó a los ciudadanos españoles abandonar China, como hicieron otros países europeos.

Nosotros mismos teníamos en Pekín una información limitada, básicamente procedente de los medios oficiales chinos. La Oficina Comercial española en Hong Kong nos prestó entonces una asistencia que para nosotros tuvo un enorme valor. Diariamente, el consejero comercial en Hong Kong, Manuel García Aranda, preparaba una selección de las noticias más destacadas de los periódicos (tanto locales, de Hong Kong, como internacionales) y nos las mandaba por fax. Recuerdo la impaciencia con que esperábamos oír el ruido de la máquina del fax al ponerse en marcha, a media mañana, y que empezaran a salir las hojas con las noticias. Se me ocurrió pasar una copia del «resumen de prensa» al embajador. A partir de ese momento todos los días me lo reclamaban con impaciencia desde la cancillería de la embajada, desde la que llamaban para preguntar si no había llegado todavía el resumen, que el embajador lo estaba esperando. 
Con técnicos españoles que se encontraban por motivos de trabajo en China tuvimos situaciones muy variadas. Desde España recibimos la petición de comunicar con varios de ellos, ya que su empresa o sus familiares no lograban contactar. Cuando conseguíamos comunicar con ellos, después de mayores o menores dificultades, les dábamos información y les decíamos que había una recomendación de abandonar China. Recuerdo que uno de estos técnicos, con el que nos costó mucho contactar, me respondió que él no se iba a marchar, que los de las empresas de la competencia seguían allí y que por tanto él también se quedaba.

En otro caso contactamos con un técnico que se encontraba en un pueblo en el norte, donde no había habido incidentes y existía en principio normalidad. La empresa española no lograba hablar con él desde España y nosotros hacíamos de «intermediarios». El director de la empresa china, en la que el técnico español estaba supervisando un montaje de maquinaria, me mandó un mensaje con un tono y contenido muy «oficialistas»: en Pekín había habido una «revuelta contrarrevolucionaria», esta ya estaba controlada y no había ninguna razón para que el técnico se marchara. Desde la empresa española me pidieron que, en su nombre, diera al técnico instrucciones terminantes para que saliera de China.

Una de las claves en la actuación de España en China fue la política mantenida por nuestro país tras los sucesos de Tiananmen, una política moderada que se opuso a sanciones duras que tuvieran como consecuencia aislar a China. Esta visión fue acertada, en mi opinión, ya que la mejor forma de favorecer la democracia y los derechos humanos en China no era a través de sanciones económicas, que dañarían en primer lugar a la población, sino a través de su integración, en todos los aspectos, en la comunidad internacional ${ }^{1}$.

Frente a la creencia de que las sanciones favorecerían la democracia, el planteamiento alternativo señalaba que sanciones económicas excesivamente duras podrían tener efectos contraproducentes, contrarios a los buscados. Una política de sanciones duras podría hacer que las autoridades chinas se sintieran acorraladas, y podría empujarlas a una huida hacia adelante, a prescindir del freno exterior y a lanzarse tanto a una política de represión más dura como hacia el aislamiento. No era favoreciendo el aislamiento exterior y el atraso económico de China como mejor se promoverían las libertades y los derechos humanos, sino, por el contrario, fomentando el desarrollo económico y la interrelación con el resto del mundo.

A raíz de la crisis de Tiananmen, España mantuvo, y defendió en el seno de la Unión Europea, una política moderada, que procuraba evitar el aislamiento de China. Gracias a ello España alcanzó un claro reconocimiento en el país asiático. Uno de los gestos más significativos, y simbólicos, de la actitud española fue la visita que realizó a China, a fines de 1990, el ministro español de Asuntos Exteriores, Francisco Fernández Ordóñez: fue la primera visita que un ministro de Asuntos Exteriores de la Unión Europea efectuaba a China tras los sucesos de Tiananmen.

Por parte de los gobernantes chinos, la actitud inmediata fue reafirmar con la máxima claridad posible que la crisis de Tiananmen no había afectado a las líneas generales de la política de reforma y apertura al exterior. Aunque siempre han sido muy celosos, rechazando todo $D$

1 Sobre los sucesos de Tiananmen, y mis recuerdos, puede ver mi ebook Memoria de Tiananmen. Una primavera de Pekín. Disponible en: http://iberchina.org/index.php?option=com_content\&view=article\&id=1169 
aquello que pudiera ser visto como injerencia exterior $-\mathrm{y}$ las condenas a los sucesos de Tiananmen eran tenidas por tales- y evitando actitudes que pudieran ser interpretadas como de debilidad, los dirigentes chinos mostraron una voluntad decidida de recomponer sus vínculos con la comunidad internacional, como así sucedió paulatinamente. 
